\title{
Analisis Seismisitas Dari Kepualuan Mentawai Pada Periode 2010-2016
}

\author{
Muhammad Ifanun Naim*, Supriyadi, Suharto Linuwih \\ Departemen Fisika Fakultas Matematika dan IPA, Universitas Negeri Semarang \\ Lantai 2 Gedung D7, Sekaran Campus, Gunungpati, Semarang 50229 \\ *Email: m.ifanun@gmail.com
}

\section{ABSTRACT}

Mentawai archipelago is a part of Sumatera Island which has two active tectonic plates. Those two tectonic plates are Indo-Australi plate which stabbed the Eurasia plate which forms a subduction zone of Sumatera which causes earthquakes. This study is aimed to examine the earthquake fault viewed from the magnitudes scale by using focal mechanism method for a casestudy of the earthquake in Mentawai archipelago on 2010-2016 period. Focal mechanism method is a method which is used to define the fault plane as the result of the earthquake by utilizing the first motion of $\mathrm{P}$ wave. The first motion of the $\mathrm{P}$ wave is in the form of compression and dilatation. Beside the use of focal mechanism method, an earthquake cross section for certain areas is also examined in this study. The aim for cross section is to see the indication of the earthquake happens in a tectonic plate. The result of the focal mechanism showed that earthquake with magnitude $\geq 6.0 \mathrm{Mw}$, the average earthquake results a reverse fault with several certain dip. The result of the cross section earthquake showed that the distribution of the hypocenter tends to stab. These events are the indication that the location of those earthquakes is the stabbed plate and when it is connected to the focal mechanism result, it also shows that the tendency of the fault is a reverse fault with several certain dip.

Keywords: seismicity, focal mechanism, fault, cross section

\section{ABSTRAK}

Kepulauan Mentawai merupakan bagian dari Pulau Sumatera yang terdapat dua lempeng tektonik yang aktif. Kedua lempeng tektonik tersebut yaitu lempeng Indo-Australi menunjam ke arah lempeng Eurasia dan menimbulkan zona subduksi Sumatera yang banyak menimbulkan kejadian gempabumi. Penelitian ini bertujuan untuk mengetahui sesar gempa ditinjau dari besarnya magnitudo dengan menggunakan metode focal mechanism studi kasus gempa pada Kepulauan Mentawai periode tahun 2010-2016. Metode focal mechanism merupakan metode untuk menentukan bidang sesar yang dihasilkan oleh kejadian gempa dengan memanfaatkan gerak awal gelombang P. Gerak awal gelombang $\mathrm{P}$ berupa gaya kompresi ataupun dilatasi. Selain dengan metode focal mechanism, dalam penelitian ini juga dibuat cross section gempa dengan luasan daerah tertentu yang bertujuan untuk mengetahui indikasi gempa yang terjadi merupakan gempa pada daerah lempeng tektonik. Hasil solusi focal mechanism untuk data gempa bermagnitudo $\geq 6.0 \mathrm{Mw}$ rata-rata gempa menghasilkan sesar naik (thrust/reverse) dengan beberapa nilai kemiringan (dip) tertentu. Sedangkan hasil dari cross section gempa menunjukkan sebaran hiposenter gempa yang cenderung menunjam. Kejadian ini adalah indikasi bahwa lokasi gempa-gempa tersebut merupakan tempat lempeng yang menunjam dan ketika dihubungkan dengan hasil focal mechanism juga menunjukkan kecenderungan sesarnya adalah sesar naik dengan beberapa nilai kemiringan (dip) tertentu

Kata kunci: seismisitas, focal mechanism, sesar, cross section

\section{PENDAHULUAN}

Kepulauan Mentawai merupakan wilayah yang aktif dalam kegempaan (seismisitas) terbukti dari rekaman kejadian gempa yang terjadi baik yang bermagnitudo kecil maupun besar selama periode 2010-2016. Kepulauan Mentawai termasuk dalam wilayah tektonik Sumatera terdapat penunjaman lempeng tektonik Indo-Australi ke Pulau Sumatera ${ }^{[1]}$. Tingkat korvergensi dari penunjaman tersebut berkisar $45 \mathrm{~mm} / \operatorname{tahun}^{[2]}$. Kepulauan 
Mentawai terdapat Sesar Mentawai dilepas pantai Sumatera Barat yang tepat berada pada batas zona subduksi Sumatera dengan Sesar Sumatera ${ }^{[3]}$.

Gempa yang terjadi sepanjang wilayah zona subduksi Sumatera umumnya menghasilkan sesar dip-slip sampai ke arah oblique ${ }^{[4]}$. Sedangkan gempa Kepulauan Mentawai menghasilkan sesar yang curam ${ }^{[5]}$. Gempa lokal pada wilayah ini secara terus menerus akan menimbulkan longsoran bawah laut dan akan membangkitkan gelombang seismik yang nantinya menimbulkan tsunami ${ }^{[6]}$. Pada segmen Mentawai setelah terjadinya gempabumi besar 25 Oktober 2010 ternyata masih menyimpan energi potensial gempabumi yang setara $7,2 \mathrm{SR}^{[7]}$. Hal itulah yang menjadikan Kepulauan Mentawai menjadi kajian dalam analisis seismisitas untuk mengetahui karakteristik bentuk sesar yang dihasilkan karena kondisi tektonik yang sangat kompleks seperti yang telah dijelaskan diatas.

Analisis seismisitas dengan menggunakan diagram focal mechanism merupakan metode yang mempermudah dalam mengetahui jenis sesar yang dihasilkan gempa. Diagram focal mechanism menghasilkan parameter sesar berupa strike, dip dan rake/slip ${ }^{[8]}$. Strike merupakan jurus dari sesar, dip adalah kemiringan sesar, dan rake/slip adalah pergerakan hanging-wall terhadap strike. Menurut USGS terdapat empat jenis sesar yang dibentuk dari diagram focal mechanism seperti pada Gambar 1 yaitu sesar geser (strike-slip), sesar turun (normal), sesar naik (reverse/thrust), dan sesar oblique.

\section{Schematic diagram of a focal mechanism}

A

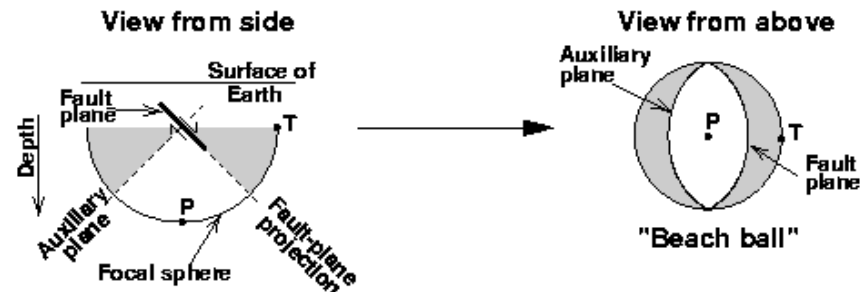

B

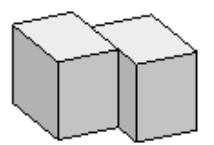

Strike slip
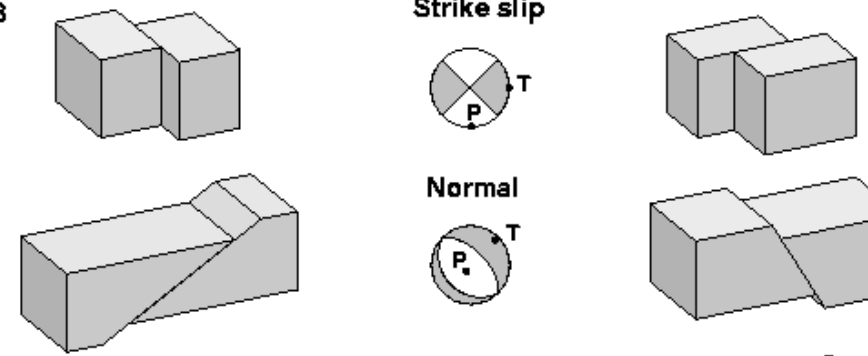

Normal
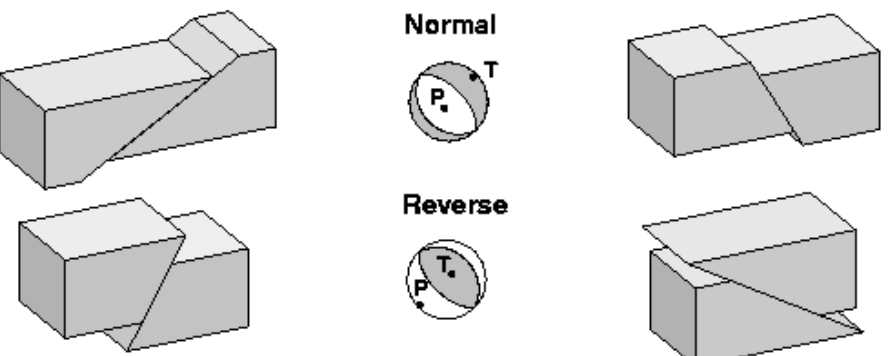

Reverse
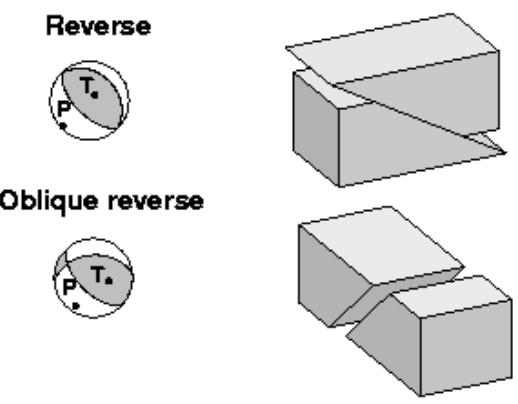

USGS, 1996

Gambar 1. Diagram focal mechanism 
Cross section gempa merupakan proses pengolahan data gempa yang bertujuan untuk mengetahui trend kemiringan data gempa. Hasil dari cross section berupa titik-titik kedalaman hiposenter gempa dari setiap luasan yang dibuat. Hal itu membantu dalam analisis seismisitas dalam hubungannya dengan kondisi tektonik wilayah terjadinya gempa.

\section{METODE}

Penelitian ini dilakukan dengan cara melakukan pengamatan pada data sintetis gempabumi dari website European-Mediterranean Seismological Centre (EMSC) dengan lokasi Kepulauan Mentawai Tahun 2010-2016. Batas data yang digunakan $2^{\circ} \mathrm{LS}$ sampai $4^{\circ} \mathrm{LS}$, $100^{\circ} \mathrm{BT}$ sampai $101^{\circ} \mathrm{BT}$. Parameter data gempa meliputi, episenter, kedalaman, magnitudo, dan bentuk diagram focal mechanism (magnitudo $\geq 6,0 \mathrm{Mw}$ ).

Pengolahan data menggunakan software Generic Mapping Tools (GMT) untuk plot data diagram focal mechanism dan cross-section pada wilayah penelitian. Pada cross-section, luasan cross-section terbagi menjadi 3 bagian yaitu luasan $\mathrm{AB}, \mathrm{CD}$, dan EF. Masing-masing luasan dengan panjang lintasan $176 \mathrm{~km}$ dan lebar $80 \mathrm{~km}$.

\section{HASIL DAN PEMBAHASAN}

Penelitian ini menggunakan metode focal mechanism untuk menentukan bentuk sesar yang dihasilkan dari data kegempaan Kepulauan Mentawai tahun 2010-2016. Data kejadian gempa tersebut diperoleh dari website European-Mediterranean Seismological Centre (EMSC). Batas data gempa Latitude (lintang) $2^{\circ} \mathrm{LS}$ sampai $4^{\circ} \mathrm{LS}$, batas longitude (bujur) $100^{\circ} \mathrm{BT}$ sampai $101^{\circ} \mathrm{BT}$. Parameter data gempa yang digunakan meliputi, episenter, kedalaman, magnitudo, dan gerak awal gelombang $\mathrm{P}$ dari setiap data gempa yang terekam oleh stasiun.

Melakukan pengolahan focal mechansim yang dihasilkan dari masing-masing data kejadian gempa. Dari hasil focal mechanism selanjutnya melakukan tahap pembuatan cross section gempa (cross section) yang dapat menghasilkan gambaran sebaran titik-titik hiposenter gempa berdasarkan kedalamannya.

\section{Focal Mechanism}

Pada pengolahan focal mechanism memanfaatkan data gerak awal gelombang $\mathrm{P}$ (kompresi/dilatasi) yang terekam oleh masing-masing stasiun terhadap setiap kejadian gempa. Kemudian mengolah data tersebut dengan bantuan software Azmtak. Data yang digunakan yaitu data gempabumi yang bermagnitudo $\geq 6,0 \mathrm{Mw}$ pada Tabel 1 yang telah terjadi di Kepulauan Mentawai tahun 2010-2016.

Hasil pengolahan focal mechanism sesuai data pada Tabel 1 ditunjukkan Gambar 2 yang berupa peta sebaran focal mechanism dari setiap data gempabumi pada wilayah penelitian. Plot peta sebaran focal mechanism dihasilkan dengan bantuan software Generic Mapping Tools (GMT). 


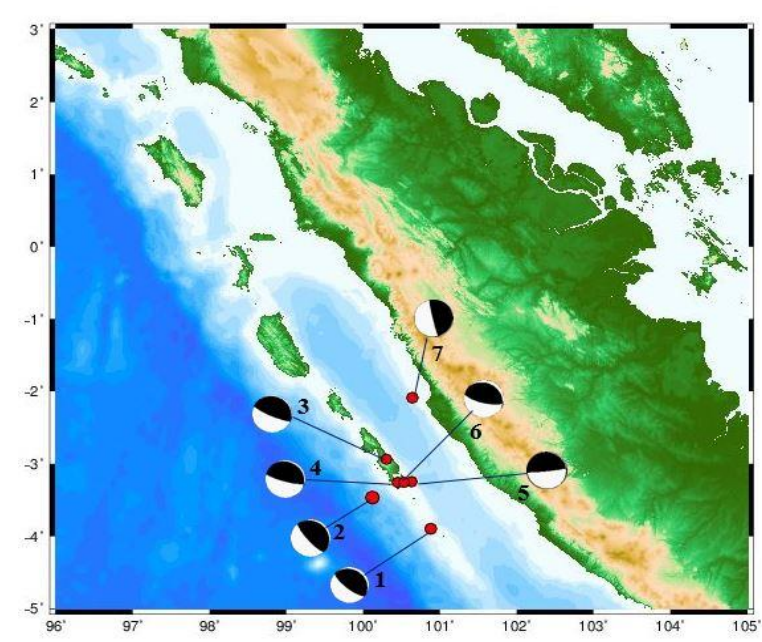

Gambar 2. (color online)Focal mechanismgempabumi Kepulauan Mentawai tahun2010-2016 (magnitudo $\geq 6,0 \mathrm{Mw}$ )

Tabel 1. Gempabumi Kepulauan Mentawai tahun 2010-2016 (Magnitudo $\geq 6,0 \mathrm{Mw}$ )

\begin{tabular}{ccccccc}
\hline No & Date & Time & Latitude & Longitude & $\begin{array}{c}\text { Depth } \\
(\mathrm{Km})\end{array}$ & $\begin{array}{l}\text { Magnitude } \\
(\mathrm{Mw})\end{array}$ \\
\hline 1 & $05-03-10$ & 16.06 .58 & -3.90 & 100.88 & 10 & 6.6 \\
2 & $25-10-10$ & 14.42 .21 & -3.47 & 100.12 & 10 & 7.7 \\
3 & $25-10-10$ & 19.37 .31 & -2.94 & 100.30 & 16 & 6.1 \\
4 & $25-10-10$ & 22.59 .54 & -3.26 & 100.45 & 20 & 6.1 \\
5 & $14-09-12$ & 04.51 .50 & -3.25 & 100.63 & 30 & 6.2 \\
6 & $06-07-13$ & 05.05 .08 & -3.26 & 100.53 & 30 & 6.0 \\
7 & $01-06-16$ & 22.56 .02 & -2.09 & 100.64 & 55 & 6.4 \\
\hline
\end{tabular}

\section{Cross Section Gempa}

Cross section gempa pada penelitian ini dibuat untuk mempermudah dalam menganalisis hubungan kejadian gempa yang terjadi dengan kondisi tektonik yang terdapat di wilayah penelitian. Cross section tersebut terbagi tiga luasan yaitu luasan daerah $\mathrm{AB}, \mathrm{CD}$, dan $\mathrm{EF}$. Hasil cross section gempa tersebut pada Gambar 3. Padacross section gempa,titik episenter dan hiposenter gempa berupa bulatan putih (०) untuk gempa yang dibawah magnitudo 6.0 Mw. Sedangkan bulatan merah $(\bullet)$ adalah gempa yang bermagnitudo $\geq 6.0 \mathrm{Mw}$. 


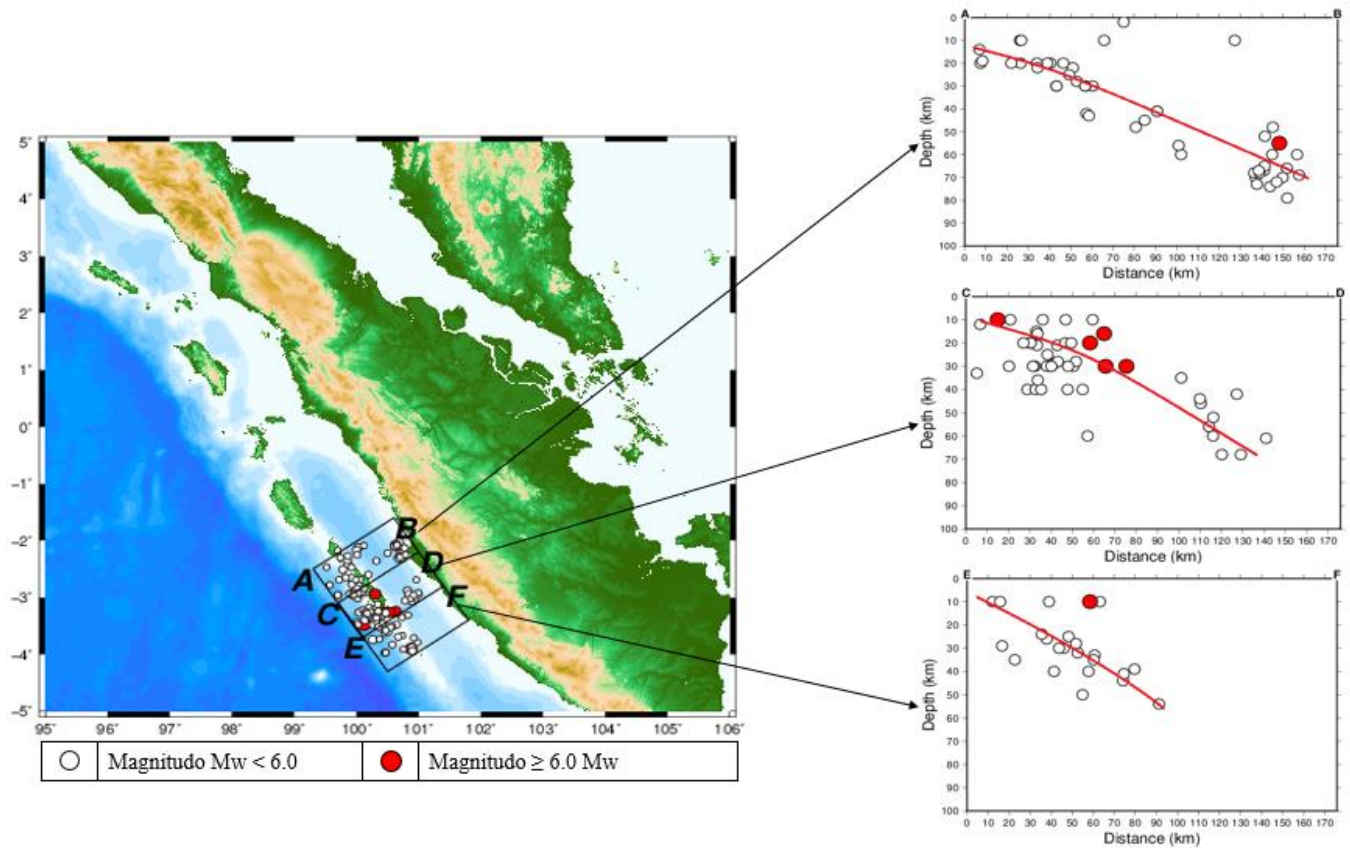

Gambar 3. (coloronline) Cross sectiongempabumi Kepulauan Mentawai tahun 2010-2016

Pada periode tahun 2010 sampai tahun 2016 telah terjadi tujuh kejadian gempa yang sangat signifikan yaitu bermagnitudo $\geq 6.0 \mathrm{Mw}$ seperti pada Tabel 1 . Gempa yang relatif bermagnitudo besar tersebut menghasilkan sesar yang cenderung vertikal. Hal ini terbukti dengan bentuk hasil solusi focal mechanism dari ketujuh gempa itu nilai parameter rake/slip bernilai positif maka jenis sesarnya adalah naik (thrust/reverse) dengan nilai kemiringan (dip) tertentu. Hasil focal mechanism tersebut juga didukung oleh penelitian sebelumnya bahwa gempa yang terjadi pada wilayah dekat zona subduksi Sumatera merupakan gempa yang menghasilkan sesar yang relatif ke arah vertikal dengan nilai kemiringan tertentu ${ }^{[4]}$. Sedangkan menurut Setyonegoro(2011) ${ }^{[9]}$, gempa menghasilkan sesar naik banyak terjadi pada kawasan zona subduksi Sumatera. Analisis mekanisme fokus kejadian gempa oleh USGS pada wilayah tersebut juga menunjukkan sesar yang dihasilkan adalah jenis sesar naik. Parameter arah jurus (strike) yang relatif mengikuti arah zona subduksi Pulau Sumatera. Hal itu menunjukkan bahwa gempa yang telah terjadi adalah indikasi pengaruh pola zona subduksi dan bukan pengaruh dari Sesar Mentawai yang berada di Kepulauan Mentawai. Karena menurut Berglar et al. (2010) ${ }^{[10]}$ bahwa Sesar Mentawai merupakan sesar yang aktif ke arah mendatar (strike-slip). Sedangkan hasil focal mechanism menunjukkan jenis sesar relatif ke arah vertikal yang mengindikasikan bahwa gempa yang terjadi adalah pengaruh aktivitas lempeng tektonik yang menghasilkan zona subduksi Sumatera.

Data gempa yang terjadi pada Tabel 1 juga menunjukkan kedalaman gempa terjadi relatif dangkal yaitu dengan kedalaman $\leq 30 \mathrm{~km}$. Hal itu didukung oleh penelitian sebelumnya yang dilakukan Samodra \& Chandra (2013) $)^{[11]}$, bahwa data gempa sejak tahun 1950-2013 pada wilayah Sumatera 89,93\% adalah gempa dangkal. Dalam kajian tentang kegempaan, gempa dangkal tersebut adalah salah satu penyebab terjadinya gelombang tsunami. Gelombang tsunami timbul apabila hiposenter terdapat di dasar laut dan episenter relatif dekat dengan garis pantai yang merupakan tempat pemukiman ${ }^{[12]}$.

Terdapat satu kejadian gempa yang sangat besar bermagnitudo 7,7 Mw yaitu pada tanggal 10 Oktober 2010. Gempa tersebut menimbulkan gelombang tsunami yang sangat merusak karena gempa berjenis sesar naik dan terjadi di laut pada kedalaman yang relatif dangkal. 
Namun sampai akhir tahun 2016 belum terdapat gempa-gempa lain yang setara atau melebihi gempa bermagnitudo 7,7 Mw pada wilayah Kepulauan Mentawai. Jadi, besar kemungkinan pada tahun selanjutnya akan terjadi gempa yang bermagnitudo yang sangat besar karena menurut Ardiansyah (2014) ${ }^{[7]}$ setelah kejadian gempa Mentawai 7,7 Mw pada tanggal 10 Oktober 2010, masih tersimpan energi potensial gempa yang setara 7,2 SR. Hal itulah yang menjadikan masyarakat dan pihak-pihak berwenang untuk waspada akan kemungkinan terjadinya gempa-gempa pada wilayah tersebut.

Sesuai hasil cross section gempa pada Gambar 3, masing-masing luasan menunjukkan perbedaan kedalaman pada setiap kejadian gempa. Kedalaman gempa yang paling dalam yaitu berkisar $80 \mathrm{~km}$ dari permukaan bumi. Namun rata-rata gempa yang terjadi baik itu gempa yang bermagnitudo besar maupun kecil merupakan gempa yang relatif dangkal. Data gempa yang dihasilkan pada cross section tersebut ketika ditarik suatu garis yang menghubungkan titik-titik gempa (hiposenter) dari kiri menuju kanan terlihat seperti garis yang menunjam. Titik-titik gempa tersebut semakin ke kanan dari luasan maka akan semakin dalam. Hal ini menunjukkan gempa tersebut terdapat kaitannya dengan kondisi tektonik pada wilayah penelitian. Kondisi tektonik tersebut yaitu zona subduksi Sumatera yang dekat dengan wilayah Kepulauan Mentawai. Zona subduksi tersebut disebabkan dari lempeng tektonik Indo-Australi yang menunjam ke arah lempeng Eurasia.

Akibat interaksi penunjaman lempeng tektonik Indo-Australi ke arah lempeng Eurasia memungkinkan adanya gempa-gempa yang muncul sepanjang zona subduksi Sumatera. Gempa-gempa yang dihasilkan pada zona subduksi Sumatera umumnya memiliki bentuk sesar dip-slip ${ }^{[4]}$ dan sumber gempa memiliki patahan yang curam ${ }^{[5]}$.

Dari hasil pengolahan focal mechanism dengan cross section gempa, ternyata terdapat keterkaitan satu sama lain. Ketika dihubungkan dengan hasil cross section gempa, gempagempa yang terjadi menunjukkan suatu penunjaman titik-titik hiposenter gempa ke arah Pulau Sumatera. Hal itulah yang menyebabkan bentuk solusi focal mechanism pada data gempa besar pada pengolahan focal mechanism cenderung membentuk sesar naik karena pengaruh pola penunjaman pada zona subduksi. Jadi, bentuk focal mechanism maupun hasil cross section gempa memeliki kesamaan mengikuti pola zona subduksi wilayah tersebut yaitu zona subduksi yang dihasilkan oleh penunjaman lempeng Indo-Indo Australi ke arah lempeng Eurasia. Semua data gempa yang telah terjadi pada wilayah penelitian merupakan gempa yang timbul karena adanya interaksi lempeng tektonik.

\section{KESIMPULAN}

Berdasarkan hasil penelitian analisis sesar gempa tektonik dengan metode focal mechanism yang telah dilakukan, dapat disimpulkan bahwa bentuk solusi focal mechanism untuk data gempabumi yang bermagnitudo $\geq 6.0 \mathrm{Mw}$ menunjukkan jenis sesar adalah sesar naik (thrust/reverse fault) disertai dengan nilai kemiringan (dip) tertentu.

Hasil cross section data sebaran gempa menunjukkan gempa terjadi pada daerah lempeng yang menunjam. Hal ini terlihat dari sebaran hiposenter gempa yang menunjukkan kecenderungan menunjam. Kejadian ini adalah indikasi bahwa lokasi tersebut merupakan tempat lempeng yang menunjam.

\section{DAFTAR PUSTAKA}

1 Rohadi, S., Grandis,H. \& Ratag, M. A. 2008. Studi Potensi Seismotektonik sebagai Precursor Tingkat Kegempaan di Wilayah Sumatera. Jurnal Meteorologi dan Geofisika, 9 (2), 101-108. 
2 Chlieh, M., Avouac, J. P., Sieh, K., Natawidjaja,D. H. \& Galetzka, J. 2008. Heterogeneous Coupling of the Sumatran Megathrust Constrained by Geodetic and Paleogeodetic Measurements. Journal of Geophysical Research, 113 (B5), 1-31.

3 Mukti, M. M., Singh,S. C., Deighton,I., Hananto,N. D., Moeremans, R.\& Permana, H. 2012. Structural Evolution of Backthrusting in the Mentawai Fault Zone, offshore Sumatran Forearc. Geochemistry Geophysics Geosystems, 13 (12), 1-21.

4 Cook, B. J., Henstock,T. J., McNeill,M. C.\&Bull, J. M. 2014. Controls on Spatial and Relationships to Plate Boundary Slip Offshore North-Central Sumatra. Journal of Geophysical Research: Solid Earth, 119 (7), 5594-5612.

5 Balakina, L. M., \& Moskvina, A. G. 2015. Andaman-Sumatra Island Arc: III. Time Evolution of Seismogenic Activation of the Arc since the Beginning of the $21^{\text {th }}$ Century. Physics of the Solid Earth, 51 (2), 219-249.

6 Singh, S. C., Hananto,N. D., Chauhan,A. P. S., Permana,H., Denolle, M., Hendriyana, A. \& Natawidjaja, D. 2010. Evidence of Active Backthrusting at the NE Margin of Mentawai Islands, SW Sumatra. Geophysical Journal International, 180 (2), 703-714.

7 Ardiansyah, S. 2014. Energi Potensial Gempabumi di Kawasan Segmen MentawaiSumatera Barat (0,5 LS - 4,0 LS dan 100 BT - 104 BT). Physics StudentJournal, 2 (1), $1-9$.

8 Supriyadi, Khumaedi, \& Fiandralekha. 2013. Studi Kasus Focal Mechanism Solution Gempa Di Selat Sunda 26 Agustus 2008 Berdasarkan Gerak Awal Gelombang dan Bentuk Gelompang P. Jurnal Sain dan Teknologi, 11 (1), 83-92.

9 Setyonegoro, W. 2011. Tsunami Numerical Simulation Applied to Tsunami Early Warning System Along Sumatra Region. Jurnal Meteorologi dan Geofisika, 12 (1), 21 32.

10 Berglar, K., Gaedicke,C., Franke,D., Ladage,S., Klingelhoefer, F. \& Djajadihardja, Y. S. 2010. Structural Evolution and Strike-slip Tectonics of North-western Sumatra. Tectonophysics, 480 (1-4), 119-132.

11 Samodra, S. B. \& Chandra, V. R. 2013. Karakteristik Gempabumi di Sumatera dan Jawa Periode Tahun 1950-2013. Prosiding Seminar Nasional Kebumian Ke-6. Universitas Gadjah Mada, Yogyakarta, 314-326.

12 Naryanto, H. S. 2008. Analisis Potensi Kegempaan dan Tsunami di Kawasan Pantai Barat Lampung Kaitannya dengan Mitigasi dan Penataan Kawasan. Jurnal Sains dan Teknologi Indonesia, 10 (2), 71-77. 